\title{
Suspeita de febre familiar dos cães shar-peis chineses
}

\author{
Suspected familiar chinese shar-pei dog fever
}

\author{
Marcia Regina da Silva Ilha ${ }^{1}$ Alexandre Paulino Loretti ${ }^{2}$ \\ Claudio Severo Lombardo de Barros ${ }^{3}$
}

\section{RESUMO}

\begin{abstract}
A febre (síndrome) familiar dos cães Shar-peis Chineses é uma doença hereditária autossômica recessiva. Este trabalho descreve um caso de amiloidose generalizada em um cão Shar-pei Chinês, fêmea, de três anos de idade, cujo quadro clínico-patológico é consistente com o da febre familiar dos cães Shar-peis chineses. Esse animal tinha uma história clínica de edema bilateral recidivante na região do jarrete que vinha sendo observado desde os sete meses de idade. Três dias antes da morte, esse cão apresentou anorexia, apatia, vômito e diarréia. À necropsia, ambos os rins estavam firmes, pálidos e possuíam a superfície capsular irregular. Histologicamente foram observados depósitos de amilóide nos rins, no pâncreas, na tireóide e no baço. Esse amilóide perdeu sua afinidade para o vermelho Congo, quando utilizado o permanganato de potássio. Esse achado é consistente com amiloidose do tipo AA.
\end{abstract}

Palavras-chave: amiloidose, febre familiar do Shar-pei Chinês, uremia, doença renal.

\section{ABSTRACT}

Chinese Shar-pei familial fever is a breedassociated hereditary autosomal recessive disease of Chinese
Shar-pei dogs. A case of generalized amyloidosis in a 3year-old female Chinese Shar-pei dog with a tentative diagnosis of familial Chinese Shar-pei fever is described. This animal had a clinical history of episodic bilateral swelling of the tarsal joints since 7-month-old. Vomiting, diarrhea, anorexia and lethargy were observed 3 days prior to death. At necropsy, both kidneys were firm, whitish and had an irregular capsular surface. Microscopically, amyloid deposits were observed in the kidneys, pancreas, thyroid glands and spleen. Amyloid deposits lost their affinity for Congo red after treatment with potassium permanganate indicating $A A$ type amyloidosis.

Key words: amyloidosis, Chinese Pei familial fever, uremia, renal disease.

Em seres humanos e animais, existem formas familiares ou hereditárias de amiloidose. Essas enfermidades são geneticamente determinadas e podem ser autossômicas dominantes ou recessivas. Em cães e gatos, formas familiares de amiloidose têm sido descritas. Uma predisposição hereditária para amiloidose tem sido observada em gatos Abissínios (DIBARTOLA et al., 1986) e cães Shar-peis Chineses

${ }^{1}$ Médico Veterinário, Mestre, Rua Paissandú, n. 385, apto. 201. Flamengo, 22210-080; Rio de Janeiro, RJ, Brasil. E-mail: ilha76@hotmail.com. Autor para correspondência.

${ }^{2}$ Médico Veterinário, Mestre, Professor Assistente 3, Setor de Patologia Veterinária, Departamento de Patologia Clínica Veterinária,

Faculdade de Veterinária, Universidade Federal do Rio Grande do Sul (UFRGS), CP 15094, 91540-000, Porto Alegre, RS, Brasil.

${ }^{3}$ Médico Veterinário, PhD, Professor Titular, Departamento de Patologia, Universidade Federal de Santa Maria (UFSM), Avenida Roraima, s/n, Campus Universitário, 97105-900, Santa Maria, RS, Brasil. 
(SPC) (DIBARTOLA et al., 1990, MAY et al., 1992, RIVAS et al., 1992, RIVAS et al., 1993, LOEVEN, 1994, TELLIER, 2001). Casos esporádicos de amiloidose afetando famílias ou indivíduos aparentados têm sido observados em cães das raças Beagle (BOWLES \& MOSIER, 1992), Grey Collie(DIGIACOMO et al., 1983) e English Foxhound (MASON \& DAY, 1996) e também em gatos Siameses (VAN DER LINDE-SIPMAN et al., 1997).

A febre familiar dos cães Shar-peis Chineses (FFS) tem muitas características em comum com a Febre Familiar do Mediterrâneo (FMF) que afeta seres humanos. Essa síndrome em SPC também é conhecida como amiloidose renal familiar dos SPC, febre recorrente (recidivante) de origem desconhecida (RFUO) (RIVAS et al., 1992), síndrome do inchaço do jarrete (articulação dos ossos do tarso), febre do jarrete, febre do Shar-pei (TELLIER, 2001) e síndrome da febre dos SPC (MAY et al., 1992). No Brasil, essa doença é conhecida como febre dos Shar-peis entre os criadores dessa raça.

O aumento crescente de criações de Sharpeis Chineses no Brasil e a progressiva difusão da raça no território nacional torna necessária a divulgação no meio veterinário da febre do Shar-pei Chinês, doença hereditária grave que pode levar os cães à morte quando adultos. O objetivo deste trabalho é descrever a história e os aspectos clínicos e patológicos de um cão Shar-pei Chinês com suspeita de desenvolver essa síndrome e divulgar informações sobre esta enfermidade no meio veterinário.

Os dados relativos ao animal e a história clínica foram obtidos através de consulta ao proprietário e veterinário responsável. Tratava-se de um cão, fêmea, Shar-pei Chinês, de três anos de idade. Aos quatro meses e meio, esse animal desenvolveu lesões cutâneas eritematosas e não-pruriginosas. Aos seis meses, as lesões de pele consistiam em eritema e alopecia afetando inicialmente a região ventral e se expandindo para o resto do corpo com exceção da face. O prurido era leve ou ausente. Esse animal foi tratado com anti-inflamatórios não-esteroidais, corticóides, antibióticos e acaricidas de uso dermatológico. Entretanto, não houve melhora das lesões cutâneas. Biópsias de pele e outros testes laboratoriais complementares não foram realizados de modo que o diagnóstico etiológico da dermatose não foi estabelecido. A partir dos sete meses de idade, o canino começou a apresentar edema recidivante nos membros posteriores, afetando as articulações do jarrete. Aos três anos de idade, o animal apresentou vômito, diarréia, anorexia, apatia, dispnéia e dificuldade de locomoção. Esses sinais clínicos foram observados durante três dias e, após esse curto período, o cão morreu e foi necropsiado.

Fragmentos de diversos órgãos incluindo os rins, fígado, baço, pâncreas e tireóides foram colhidos à necropsia e fixados em formol tamponado a $10 \%$. Um fragmento do rim direito fixado em formol foi embebido em solução a base de lugol por aproximadamente 5 minutos e em seguida mergulhado em ácido sulfúrico a $10 \%$ por cerca de 3 minutos. Os tecidos colhidos à necropsia foram processados rotineiramente para exame histológico, incluídos em parafina, cortados a $5 \mathrm{~mm}$ e corados pela Hematoxilina \& Eosina (H-E) e impregnação pela prata de Gomori. Adicionalmente, cortes histológicos de rim e de baço foram corados pelo Vermelho Congo. O método do permanganato de potássio para diferenciação entre amilóide do tipo AA [associado à amilóide, derivada da proteína SAA (proteína associada à amilóide sérico) produzida pelo fígado] e amilóide do tipo AL [amilóide de cadeia leve, derivada das cadeias leves de imunoglobulinas (produzidas pelos plasmócitos)] foi utilizado em cortes histológicos de rim e baço que posteriormente também foram corados com Vermelho Congo.

À necropsia, foram observadas lesões macroscópicas típicas de um quadro de insuficiência renal crônica. Ambos os rins estavam diminuídos de tamanho. O rim esquerdo tinha tamanho menor que o rim direito (dois terços do rim direito). Os rins estavam mais firmes, pálidos e possuíam superfície capsular irregular. Na superfície capsular e de corte do rim esquerdo, havia vários cistos de até $3 \mathrm{~mm}$ de diâmetro. A superfície de corte de ambos os rins era brancacenta, firme e com múltiplos pontos translúcidos de $1 \mathrm{~mm}$ no córtex. Quando um fragmento de rim foi colocado em solução de lugol, observou-se que os diminutos pontos na região cortical dos rins ficaram marrons. Estrias localizadas na região medular assumiram coloração semelhante. Esses pontos e estrias tornaram-se púrpuras quando o fragmento do rim foi mergulhado em ácido sulfúrico (Figura 1). Essa reação indicou a deposição de amilóide nessas estruturas do parênquima renal. Lesões extra-renais de uremia incluíam ulcerações na face ventral da língua e várias erosões de até $0,5 \mathrm{~cm}$ de diâmetro na região fúndica do estômago.

Histologicamente, observaram-se, em ambos os rins, depósitos de substância fracamente eosinofílica e homogênea ou levemente fibrilar no tufo glomerular, principalmente no rim esquerdo. Esse material extra-celular também era observado em algumas áreas do interstício da região medular e em menor quantidade no córtex. Na luz dos túbulos renais, 


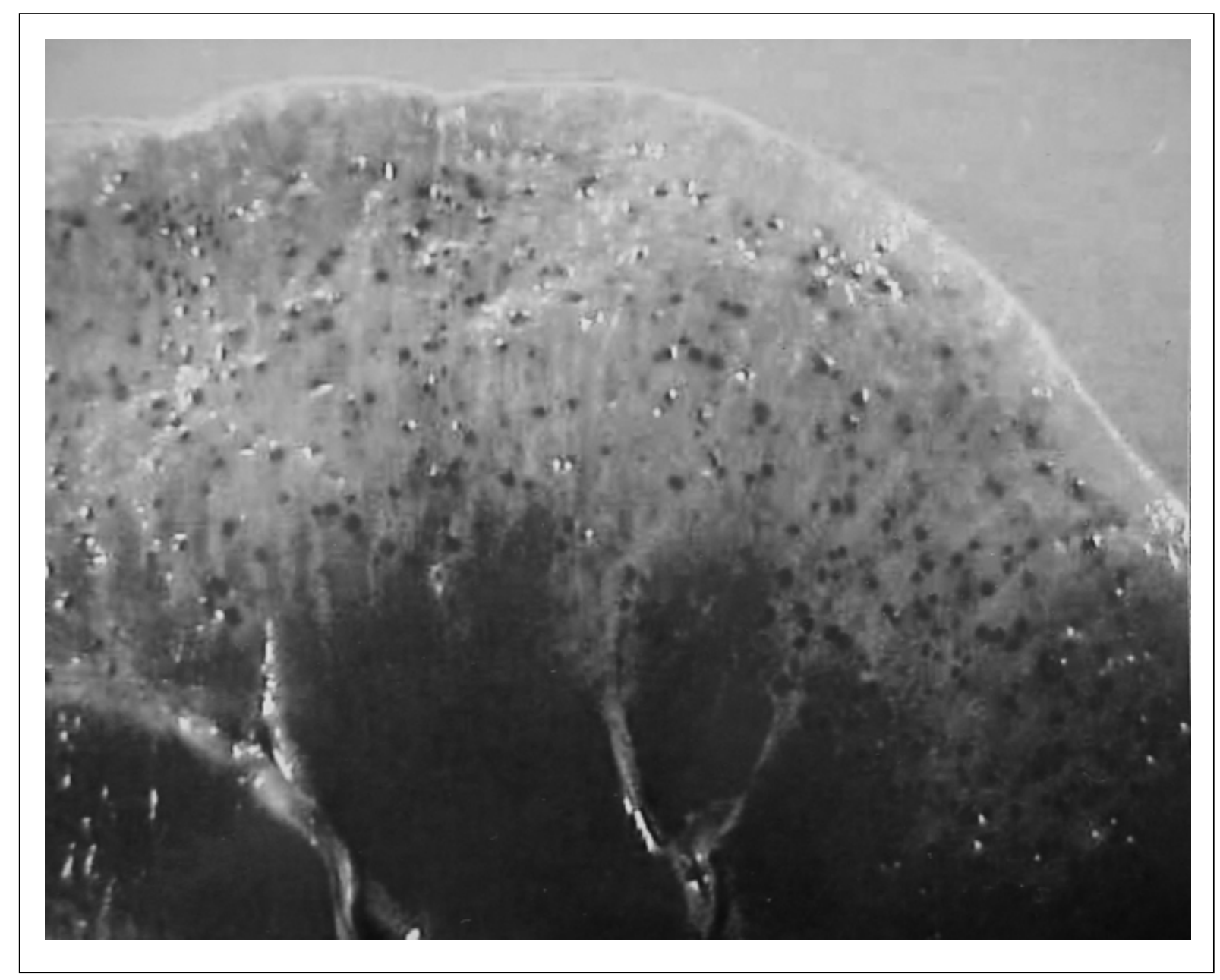

Figura 1 - Suspeita de febre familiar dos cães Shar-peis Chineses. Superfície de corte do rim fixado em formol e corado com iodo e ácido sulfúrico. O tratamento da amostra de tecido com essa solução evidenciou múltiplos pontos escuros de $1 \mathrm{~mm}$ de diâmetro no córtex do rim que correspondem aos depósitos de amilóide nos glomérulos renais.

havia quantidade moderada de cilindros eosinofílicos e hialinos (proteinose tubular). Observaram-se também fibrose intersticial leve e infiltrado linfoplasmocitário multifocal, leve, principalmente no córtex renal. Material extracelular semelhante àquele observado no rim também estava presente no interstício do pâncreas e da tireóide e nas arteríolas do baço. Nos cortes corados com Vermelho Congo, o material extracelular observado em diferentes órgãos e tecidos tornou-se verde birrefringente ao microscópio de luz polarizada. Os depósitos de amilóide foram sensíveis ao tratamento com o permanganato de potássio, indicando tratar-se de amilóide do tipo AA. Na coloração da prata de Gomori não foi observado espessamento das membranas basais glomerulares.

Neste caso, o diagnóstico de amiloidose AA generalizada de caráter familiar que afeta cães SPC foi baseado no histórico, achados clínicos e patológicos (macrocroscópicas, microscópicos e histoquímicos). A lesão primária era de amiloidose renal que causou insuficiência renal e uremia. Sinais indicativos de uremia incluíam o quadro clínico observado alguns dias antes da morte e as úlceras bilaterais simétricas na língua e as erosões no estômago observadas à necropsia. Os dados epidemiológicos e clínicos observados neste caso são semelhantes aos descritos em casos da febre familiar dos cães Shar-peis Chineses (DIBARTOLA, 1995, MAY et al., 1992, RIVAS et al., 1993). A FFS é uma doença hereditária autossômica recessiva. Entretanto, ainda não foi definido se essa é uma doença autossômica recessiva poligênica ou associada a um único gene (RIVAS et al., 1993). A patogenia dessa enfermidade ainda não está totalmente esclarecida (RIVAS et al., 1992).

Ciência Rural, v.35, n.3, mai-jun, 2005. 
Neste relato, o cão apresentou inicialmente sinais clínicos consistentes com a febre recorrente (recidivante) de origem desconhecida (RFUO) e posteriormente manifestações compatíveis com a amiloidose renal (RA). Deve ser ressaltado que nem sempre os episódios de febre recorrente e a amiloidose sistêmica ocorrem no mesmo cão. Sinais de RFUO geralmente são observados quando os animais são jovens (RIVAS et al., 1993). Neste caso, os edemas sobre as articulações do tarso começaram a ser observados a partir dos sete meses de idade mas os sinais clínicos de insuficiência renal, devido à amiloidose renal, ocorreram somente aos três anos de idade. Quando RFUO e RA ocorrem em um mesmo cão, geralmente uma média de dois anos transcorre entre as manifestações clínicas de RFUO e o início da doença renal clinicamente evidente. A maioria dos SPC afetados que desenvolvem sinais clínicos de RFUO geralmente manifestam esses sinais antes de completar 2 anos de idade (RIVAS et al., 1993).

Os depósitos renais de amilóide nos SPC afetados por esta doença diferem daqueles observados na amiloidose renal secundária, de caráter não-familiar, observada nas demais raças caninas. Nos SPC, o acúmulo de amilóide é observado não apenas nos glomérulos, mas principalmente no interstício da região medular, enquanto, nas demais raças de cães, os depósitos são predominantemente glomerulares (DIBARTOLA et al., 1989). Nesse caso, biópsias do córtex renal podem resultar em diagnósticos falso negativo, uma vez que os depósitos podem ocorrer somente na medula renal em alguns animais doentes.

Neste caso, a causa específica da doença de pele intercorrente não foi definida. Em um caso da febre familiar dos SPC, também foi observada dermatite e otite externa de etiologia não determinada (TELLIER, 2001). Recentemente, uma nova condição caracterizada por dermatopatia aguda associada à febre e apatia, edema subcutâneo generalizado e dor nas articulações foi observada em cães SPC entre 2 e 4 meses de idade. Essa condição lembra em alguns aspectos a FFS. Entretanto, uma relação direta entre a amiloidose dos SPC e esta vasculopatia recém-descrita ainda não foi comprovada (MALIK et al., 2002). Infelizmente, a discussão sobre a causa da lesão de pele no presente relato e sua associação com o quadro geral da FFS é limitada devido à escassez de dados a esse respeito.

O tratamento para essa enfermidade pode ser sintomático, quando o cão apresenta sinais clínicos de insuficiência renal ou hepática, ou profilático para reduzir a deposição de amilóide e suas conseqüências, pois uma vez havendo o depósito de amilóide não há como removê-lo. Tem sido descrito o uso de substâncias tais como Dimetilsulfóxido (DMSO) e Colchicina como medida profilática (DIBARTOLA et al., 1990, LOEVEN, 1994). A troca de e-mails com criadores e proprietários de cães da raça Shar-pei Chinês no Brasil revelou fortes indícios de que essa doença hereditária ocorre em exemplares brasileiros dessa raça. Sugere-se a identificação dos animais portadores da doença e a retirada desses animais dos programas de reprodução de modo a evitar a disseminação e perpetuação da doença no Brasil.

\section{REFERÊNCIAS BIBLIOGRÁFICAS}

BOWLES, M.H.; MOSIER, D.A. Renal amyloidosis in a family of Beagles. J Am Vet Med Assoc, v.201, n.4, p.569-574, 1992.

DIBARTOLA, S.P. et al. Pedigree analysis of Abyssinian cats with familial amyloidosis. Am J Vet Res, v.47, n.12, p.26662668, 1986.

DIBARTOLA, S.P. et al. Clinicopathologic findings in dogs with renal amyloidosis: 59 cases (1976-1986). J Am Vet Med Assoc, v.195, n.3, p.358-364, 1989.

DIBARTOLA, S.P. et al. Familial renal amyloidosis in Chinese Shar Pei dogs. J Am Vet Med Assoc, v.197, n.4, p.483-487, 1990.

DIBARTOLA, S.P. Renal amyloidosis. In: OSBORNE, C.A.; FINCO, D.R. Canine and feline nephrology and urology. Baltimore : Williams \& Wilkins, 1995.

DIGIACOMO, R.F. et al. Clinical and pathologic features of cyclic hematopoiesis in Grey collie dogs. Am J Pathol, v.111, n.2, p.224-233, 1983.

LOEVEN, K.O. Hepatic amyloidosis in two Chinese Shar Pei dogs. J Am Vet Med Assoc, v.204, n.8, p.1212-1216, 1994.

MALIK, R. et al. Acute febrile neutrophilic vasculitis of the skin of young Shar-pei dogs. Aust Vet J, v.80, n.4, p.200206, 2002.

MASON, N.J.; DAY, M.J. Renal amyloidosis in related English foxhounds. J Small Anim Pract, v.37, n.6, p.255-260, 1996.

MAY, C. et al. Chinese Shar pei fever syndrome: a preliminary report. Vet Rec, v.131, n.25-26, p.586-587, 1992.

RIVAS A.L. et al. A canine febrile disorder associated with elevated interleukin-6. Clin Immunol Immunopathol, v.64, n.1, p.36-45, 1992.

RIVAS, A.L. et al. Inheritance of renal amyloidosis in Chinese Shar-pei dogs. J Hered, v.84, n.6, p.438-442, 1993.

TELLIER, L.A. Immune-mediated vasculitis in a shar-pei with swollen hock syndrome. Can Vet J, v.42, n.2, p.137-139, 2001.

VAN DER LINDE-SIPMAN et al. Generalized AAamyloidosis in Siamese and Oriental cats. Vet Imunol and Imunopathol, v.56, n.1-2, p.1-10, 1997.

Ciência Rural, v.35, n.3, mai-jun, 2005. 